\title{
Ser gestante soropositivo para o Vírus da Imunodeficiência Humana: uma leitura à luz do Interacionismo Simbólico*
}

\author{
Being pregnant seropositive and having acquired the human immunodeficiency Virus (HIV): a theoretical \\ interpretation under the Symbolic Interactionism
}

Ser gestante seropositiva para el Virus de la inmunodeficiencia bumana-HIV: una lectura bajo el marco teórico del Interaccionismo Simbólico

\author{
Edilene Lins de Moura ${ }^{1}$, Amélia Fumiko Kimura², Neide de Souza Praça ${ }^{3}$
}

\begin{abstract}
RESUMO
Objetivo: Descrever o contexto do cotidiano vivido por mulheres grávidas soropositivas para o Vírus da Imunodeficiência Humana (HIV), com enfoque na experiência de tornar-se grávida e assumir a gravidez. Métodos: Os dados foram coletados por meio de entrevista gravada, com 14 gestantes sabidamente soropositivas para o HIV, que vivenciavam o terceiro trimestre de gravidez. O estudo fez uma leitura de dados brutos sobre expectativas e ações de gestantes soropositivas para o HIV, à luz do Interacionismo Simbólico.Resultados: um dos aspectos encontrados mostrou que as mulheres HIV positivo assumem a gravidez, ainda que esta seja inesperada. Conclusões: os dados são um alerta para os profissionais de enfermagem que devem promover ações educativas para atender às demandas dessa mulher.

Descritores: Síndrome da imunodeficiência adquirida; Gravidez; Enfermagem
\end{abstract}

\begin{abstract}
Objective: To describe the context of everyday life experienced by pregnant women seropositive for human immunodeficiency virus (HIV), focusing on the experience of becoming pregnant and accepting that condition. Methods: Data were collected recording interviews with 14 pregnant women known to be HIV positive, who experienced the third trimester of pregnancy. The study interpreted the data on expectations and actions of pregnant HIV positive, under the theoretical interpretation of the Symbolic Interactionism. Results: One aspect showed that HIV-positive women accepted the pregnancy when appeared. Conclusions: The results are warning to the nursing professionals to promote educational activities to meet the demands of this woman.
\end{abstract}

Keywords: Acquired immunodeficiency syndrome; Pregnancy; Nursing

\section{RESUMEN}

Objetivo: Describir el contexto cotidiano vivido por mujeres embarazadas y seropositivas para el virus de la inmunodeficiencia humana (HIV), con enfoque en la experiencia de estar embarazada y aceptar ese estado. Métodos: Los datos fueron recolectados por medio de entrevista grabada, con 14 gestantes sabidamente seropositivas para el HIV, que se encontraban en el tercer trimestre de embarazo. El estudio hizo una lectura de los datos brutos sobre expectativas y acciones de las gestantes seropositivas para el HIV, bajo el marco teórico del Interaccionismo Simbólico. Resultados: Uno de los aspectos encontrados mostró que las mujeres infectadas con Sida aceptan el embarazo, inclusive cuando ocurre inesperadamente. Conclusiones: Los datos sirven de para los profesionales de enfermería para que promuevan acciones educativas que atiendan las necesidades de esas mujeres.

Descriptores: Síndrome de la inmunodeficiencia adquirida; Embarazo; Enfermería

\footnotetext{
* Estudo realizado no Ambulatório de Pré-Natal do Hospital e Maternidade Escola Dr. Mário de Moraes Altenfelder Silva, localizado na zona norte do Município de São Paulo, (SP), Brasil.

${ }^{1}$ Mestre em Enfermagem. Unidade de Alojamento Conjunto, Hospital Universitário da Universidade de São Paulo - USP, São Paulo (SP), Brasil.

${ }^{2}$ Doutora em Enfermagem. Professora do Departamento de Enfermagem Materno - Infantil e Psiquiátrica da Escola de Enfermagem da Universidade de São Paulo - USP, São Paulo (SP), Brasil.

${ }^{3}$ Livre-Docente. Professora do Departamento de Enfermagem Materno - Infantil e Psiquiátrica da Escola de Enfermagem da Universidade de São Paulo USP, São Paulo (SP), Brasil.
} 


\section{INTRODUÇÃO}

Para as mulheres, a gravidez e a maternidade refletem expectativas sociais e culturais muito amplas que surgem no imaginário social, ligadas à saúde, à felicidade, à continuidade de sua vida, de sua família e da espécie. A gestação, em particular, induz um processo de introspecção e de preocupação da mulher para com a geração de uma criança sadia ${ }^{(1)}$.

A decisão de ter ou não um filho é determinada pelo significado que a mulher atribui à maternidade, levando em consideração as condições objetivas e subjetivas vividas em determinado momento de sua vida. Portanto, esta decisão poderá se alterar em função do significado e do sentido que a mulher atribui ao fato de ter um filho, quando analisa os riscos e os benefícios, as perdas e os ganhos, as dificuldades e as facilidades que deverá enfrentar ao assumir a gravidez. Mesmo nas situações em que a gestação não foi planejada, é inesperada ou inoportuna, a mulher tem a tendência para decidir pela sua evolução natural, decisão determinada pelo sentido e pelo significado que atribui à própria experiência.

Neste aspecto, estudo realizado com mães soropositivas para o Vírus da Imunodeficiência Humana (HIV), freqüentadoras de um ambulatório da rede pública do Município de São Paulo, mostrou que essas mães procuram demonstrar para a sociedade sua preocupação quanto à proteção do filho frente à possibilidade de infecção. Diante desta situação, buscam a aceitação da sociedade, de modo a serem vistas como cuidadoras, ao priorizar a saúde do filho ${ }^{(2)}$.

As mulheres que são mães soropositivas para o HIV tornamse, em muitos momentos de suas vidas, elementos-chave da unidade familiar. Com freqüência, as estratégias de enfrentamento individual são descritas de maneira mais global no seu contexto social. A particularidade resultante do exame de fatores que predispõem ou que motivam estilos individuais de enfrentamento pode se relacionar à perspectiva de gênero, de raça ou de etnia. Os autores de um estudo ${ }^{(3)}$. com esta abordagem defendem a necessidade de se estabelecer conhecimento com base em resultados de pesquisas para o avanço nas propostas de intervenção em enfermagem que respondam às demandas das necessidades dessa clientela.

Diante dessas considerações, o presente estudo teve como objetivo descrever o contexto do cotidiano vivido por mulheres grávidas soropositivas para o HIV, com enfoque na experiência de tornar-se grávida e assumir a gravidez, identificando as expectativas e as ações da gestante soropostitiva para o HIV quanto à gravidez e ao filho que está gerando.

\section{MÉTODOS}

Adotou-se a abordagem metodológica qualitativa. A pesquisa qualitativa caracteriza-se por: coleta de dados nos cenários naturais dos participantes do estudo, o pesquisador deve ser a pessoa que detém os dados; utiliza a análise indutiva de dados; focaliza os significados atribuídos pelos participantes à experiência vivida; o desenho de estudo é pré-estabelecido, porém pode não ser seguido rigidamente; utiliza referencial teórico para interpretar e elaborar as categorias analíticas e adota uma abordagem holística ${ }^{(4)}$.
Como referencial teórico para análise dos dados e elaboração das categorias analíticas deste estudo, adotou-se a perspectiva interacionista $^{(5)}$. O Interacionismo Simbólico valoriza o sentido que as coisas têm para o comportamento humano. $\mathrm{O}$ sentido emerge do processo de interação entre as pessoas e envolve uma interpretação que ocorre em duas etapas. Em primeira instância, o indivíduo mostra para si o sentido das "coisas", indicando um processo de interação consigo mesmo. Em seguida, o indivíduo seleciona, reavalia e classifica, transformando os sentidos à luz da situação do momento e da direção de sua ação. Na interpretação não há uma aplicação sistemática de sentidos pré-estabelecidos, trata-se de um processo de constante elaboração. A perspectiva interacionista concebe que o indivíduo manipula seu mundo, construindo a sua ação. $\mathrm{O}$ ser humano age e responde às ações dos outros, de acordo com sua interpretação do significado dessas ações. O significado dos objetos surge na interação entre as pessoas, e os significados são produtos sociais, portanto, podem ser constantemente redefinidos e reinterpretados no processo de interação ${ }^{(5)}$.

O Interacionismo Simbólico apresenta quatro idéias centrais: 1. Focaliza a natureza da interação e da atividade social entre as pessoas. Na perspectiva de se ver a interação como unidade, o indivíduo torna-se um ser ativo, rejeitando-se a imagem de passividade cujas ações são previsíveis ou determinadas pelo ambiente. 2. O indivíduo é um ser agindo no presente, influenciado pelo que está acontecendo agora, e não pelos acontecimentos do passado, considera-se que a interação é um acontecimento que ocorre no presente e as ações estão diretamente vinculadas ao sentido que atribui naquele momento. 3. Interação diz respeito ao interpessoal e intrapessoal, ou seja, o indivíduo interage com o outro e consigo, mediado por regras, valores e crenças sociais, bem como crenças, valores e motivações pessoais. 4. O indivíduo é descrito na perspectiva interacionista como um ser imprevisível e ativo em seu mundo. Os seres humanos agem segundo as próprias definições, isto envolve escolhas conscientes. $\mathrm{O}$ indivíduo guia-se a si mesmo e também se redireciona de acordo com a própria avaliação que faz de toda a situação envolvida.

O local do estudo foi o Ambulatório de Pré-Natal do Hospital e Maternidade Escola Dr. Mário de Moraes Altenfelder Silva (Maternidade Escola de Vila Nova Cachoeirinha), da rede pública, localizado na zona Norte do Município de São Paulo, referência para gestantes HIV positivo.

Foram convidadas a participar do estudo 14 gestantes soropositvas para o HIV que freqüentaram o pré-natal da instituição, no período compreendido entre agosto/2001 a fevereiro/2002. Os critérios de inclusão adotados para compor o estudo foram:

Ser soropositiva para o HIV antes da gravidez atual;

Estar assintomática no momento da coleta dos dados;

Estar no $3^{\circ}$ trimestre da gravidez.

Os dados foram obtidos por entrevista individual, usandose um formulário com questões sobre caracterização sóciodemográfica das gestantes, dados sobre a saúde da família e sobre a infecção pelo HIV. Constou, também, a seguinte pergunta aberta: Me fale como é ser HIV positivo e estar esperando um bebê? As respostas foram gravadas. 
O projeto foi aprovado, em 22/10/2001, pela Comissão de Ética em Pesquisa da Escola de Enfermagem da Universidade de São Paulo e pela Comissão de Ética do hospital campo do estudo. O princípios éticos atenderam à Resolução n. ${ }^{\circ}$ 196/96 do Conselho Nacional de Saúde. As respondentes concordaram com o Termo de Consentimento Livre e Esclarecido apresentado e assinado anteriormente à realização da entrevista.

As entrevistas foram transcritas e analisadas, na busca de identificar os significados simbólicos atribuídos pelas gestantes à experiência de engravidar na condição de soropositivas para o HIV. Dessa forma, precisou-se identificar o pensar, o sentir e o agir destas mulheres, à luz dos significados que atribuem às interações sociais com os outros significantes e consigo mesmas na experiência sob estudo. Como estratégia para analisar os dados obtidos e identificar os temas e categorias empíricas, seguindo o referencial adotado, dirigiram-se perguntas aos dados, tais como: Quais são os valores estabelecidos ou instituídos que norteiam as ações e as reações das gestantes frente a esta vivência? Como as gestantes soropositivas interagem frente às crenças, aos valores, às normas instituídas? Como agem ao atribuírem significados às interações que estabelecem consigo mesmas e com os outros significantes? Esta estratégia analítica possibilitou: identificar o sentido que as gestantes soropositivas atribuem à maternidade, identificar as motivações que as levaram a fazer escolhas e tomar as decisões, bem como conhecer as formas de enfrentamento da doença, de autocuidado na gravidez, os fatores intervenientes que facilitaram ou dificultaram a vivência de ser/estar grávida soropositiva e suas expectativas e esperanças quanto ao futuro.

Os relatos foram lidos repetidamente e deles foram extraídos trechos, que, por meio do processo de codificação levaram à elaboração das categorias e dos temas emergentes. A codificação adotada na fase inicial de leitura e análise dos dados consiste em identificar os temas, os conceitos, as interpretações, a tipologia e as proposições. Feito isso, os dados (códigos) foram agrupados em categorias de acordo com similaridades e diferenças. Nessa etapa, identificou-se o significado dos dados não inclusos nas categorias, e averiguou-se se eles evidenciavam a constituição de novas categorias ou propriedades, bem como dimensões das categorias emergentes. O passo seguinte foi refinar a análise, verificando a existência de pontos obscuros ou contraditórios no conjunto das categorias e temas até então descobertos ${ }^{(6)}$.

A descrição da experiência estudada é apresentada segundo modelo teórico processual da vivência das gestantes soropositivas, seguindo a seqüência em que os eventos foram ocorrendo na vida das mulheres participantes do estudo. Assim, a apresentação dos resultados foi ordenada abordando inicialmente o contexto de vida das mulheres soropositivas para o HIV; em seguida, a gravidez e as expectativas quanto ao futuro.

A análise dos dados, segundo o referencial utilizado, possibilitou a identificação do seguinte fenômeno "a vivência da gravidez por mulheres soropositivas para o HIV", construído a partir de três categorias: a convivência com a soropositividade; tornar-se grávida, o que ocorre de duas formas distintas: Gravidez Inesperada e Gravidez Desejada; e Assumir a Gravidez.

Optou-se por apresentar os resultados inicialmente com a caracterização das gestantes que participaram do estudo e em seguida as categorias que emergiram dos discursos das participantes, que possibilitaram a compreensão da experiência vivida por elas.

\section{RESULTADOS}

Das 14 gestantes entrevistadas, $8(57,2 \%)$ estavam com idade entre 27 e 33 anos, $3(21,4 \%)$ entre 21 e 26 anos e $3(21,4 \%)$ com até 20 anos de idade; $10(71,4 \%)$ não exerciam atividades remuneradas no momento e $4(28,6 \%)$ estavam empregadas. A maioria (9 - 64,3\%) não havia completado o ensino fundamental e somente $3(21,4 \%)$ completaram o ensino médio.

A renda familiar de 9 gestantes $(64,3 \%)$ era entre um e quatro salários mínimos. Apenas uma gestante $(7,1 \%)$ tinha renda familiar superior a cinco salários mínimos; duas gestantes $(14,3 \%)$ viviam com menos de um salário mínimo e duas (14,3\%) não souberam referir a renda mensal da família.

Dentre as 14 mulheres, $6(42,8 \%)$ conviviam maritalmente e 8 $(57,2 \%)$ referiram estar namorando ou mantendo relacionamento casual com seus parceiros; 7 gestantes $(50 \%)$ estavam em sua $3^{a}$ ou $4^{a}$ gravidez, 4 (28,6\%) eram grandes multíparas e apenas uma $(7,1 \%)$ era primigesta; 12 mulheres $(92,9 \%)$ referiram ter filhos saudáveis e apenas uma $(7,1 \%)$ desconhecia o estado de saúde do filho por não conviver com ele. Somente três gestantes $(21,4 \%)$ planejaram esta gravidez; $6(42,8 \%)$ possuiam parceiros soropositivos para o HIV, 5 $(37,5 \%)$ tinham parceiros sorodiscordantes e $3(21,4 \%)$ desconheciam a sorologia do parceiro. No entanto, 10 gestantes $(71,4 \%)$ declararam que seus parceiros eram saudáveis.

Sete mulheres $(50 \%)$ sabiam de sua soropositividade há de um a quatro anos, $4(28,6 \%)$ conheciam a soropositividade entre cinco e oito anos, e $3(21,4 \%)$ tinham esse conhecimento entre 9 e 12 anos. Anteriormente à gravidez, 8 mulheres $(57,2 \%)$ faziam uso de antiretrovirais, e na gestação, as 14 gestantes seguiam o tratamento.

\section{A compreensão da experiência vivenciada}

1. A convivência com a soropositividade: Para as participantes, a gravidez ocorreu após terem ciência da soropositividade para o vírus da Síndrome da Imunodeficiência Adquirida (Aids). Esta categoria mostra o cotidiano vivido por estas mulheres, no contexto onde ocorreu a gravidez. Ao resgatar a experiência de estar grávida, a mulher considera os significados atribuídos a este contexto de vida.

Esta categoria mostra as crenças e os valores, dos quais derivam as reações emocionais das mulheres, quando descobrem-As mulheres passam por uma fase em que pensam na alternativa do aborto para interromper a gravidez inesperada visando poupar-se da sujeição ao tratamento, ao preconceito e à discriminação social.

Ao se deparar com a confirmação de estar soropositivas para o HIV, as mulheres apresentam reações frente a esta descoberta. Num primeiro momento, estas reações manifestam-se sob a forma de sentimentos de desespero, atribuindo à infecção um fator determinante de sua sentença de morte, levando-as a analisar seus planos pessoais e familiares. Outro sentimento que emerge é o de inconformismo e indignação, particularmente para aquelas que não se consideravam como vulneráveis à infecção pelo o vírus da Aids.

\footnotetext{
"[...] quando eu descobri que era soropositiva, entrei em desespero [...]" "[... eu fico sempre achando que vou morrer a qualquer hora [...]"
} 
Estas mulheres demonstram crença e expectativa de que, em breve, a ciência desenvolverá terapêuticas que interromperão a evolução e a manifestação da Aids. Esta esperança é movida pela fé em Deus de que, com Sua ajuda, os cientistas descobrirão a cura, e também mobiliza as mulheres para tratarem-se com os recursos atuais da medicina, enquanto aguardam a descoberta da cura definitiva.

"[...] conversando com as amigas que são soropositivas, falou pra mim que a ciência hoje está muito evoluida e, quem sabe, um dia, vai ter uma medicação, um remédio que pode negativar, até mesmo os adultos [...]"

As mulheres apropriam-se do conhecimento sobre a evolução da doença, seus sinais e sintomas, aderem ao tratamento medicamentoso, conhecem o significado do resultado dos exames laboratoriais, e adaptam o seu próprio estilo de vida para favorecer a preservação da saúde.

A aderência ao tratamento medicamentoso é uma decisão e uma ação assumida pelas mulheres como opção que as levará a prolongar e manter seu bem-estar físico. O sentido atribuído à obrigatoriedade de se medicarem diariamente é de estar em tratamento de uma doença crônica prolongada, e, para algumas mulheres, a aquisição da melhor performance física.

A atitude ativa de preservação da saúde volta-se, ainda, para quaisquer manifestações físicas diferentes que ocorrem no seu corpo.

"[... se vocêficar dando chance a esse vírus progredir épior pra você [...]"

"[...] eu sinto quando ele tá baixo porque vai saindo coisa na minha boca, vai me deixando fraca, o AZT não é o suficiente [...]"

As mulheres crêem que Deus está no controle de sua vida, que Nele podem confiar e receber forças para continuar vivendo e esperar Dele a cura, caso esta seja a Sua vontade.

"[...] Deus é tudo! Ele é tudo, quero dizer, acho que sem Ele, a gente não vai pra lugar nenhum. Se eu não confiasse Nele, eu não teria, eu não teria força nem pro primeiro, quanto mais pro segundo (filho) [...]”

As mulheres percebem que são tratadas pelas pessoas com discriminação e preconceito, por serem soropositivas para o vírus da Aids.

"[...] tem muitas pessoas.... com olhar de .... piedade, dó. A gente teria que ser tratada normal [...]"

Para preservarem-se dos preconceitos e das discriminações, as mulheres omitem e ocultam sua soropositividade, mas também quaisquer outros objetos e ações que possam estar associados, tais como medicamentos, exames e consultas médicas.

"[...] eu escondo tudo, en faço tudo pra ninguém ficar sabendo [...]"

"[...] o pessoal pergunta, pra que é? Tem muito lugar que a gente não pode explicar pra que serve, por causa do preconceito [...]"

Porém, estas mulheres não se percebem diferentes das outras mulheres e enfrentam a condição de soropositividade sem se abater, desanimar ou desistir da vida. Não fazem da infecção um drama e nem levam a vida em função da infecção.
"[...] é tudo normal, como qualquer uma outra né? Qualquer uma outra mãe sem, que não seja soropositiva [...]"

"[...] eu não deixo pegar assim na cabeça, pô, mas eu tenho HIV !!! [...]"

"[...] eu posso morrer de tudo, mas menos do soropositivo [...]"

O apoio recebido pelas mulheres é um fator que lhes dá sustentação para que não desistam de se cuidar, que lhes mostra que vale a pena tratar-se e que reforça constantemente que outras pessoas se importam e se preocupam em ajudá-las. Ser aceitas pelos familiares, poder contar com ajuda para criar os filhos e para realizar o tratamento lhes dá suporte. O serviço de saúde e os profissionais que as atendem também são elementos de apoio para estas mulheres.

"[... eu tive que deixar eles (os filhos) na Babia com a minha mãe prápoder vir em busca de tratamento, por causa que eu tava tendo uma recaída [...]"

2. Tornar-se grávida: Nesta categoria verifica-se como a gravidez passou a integrar a vida destas mulheres. Para estas gestantes soropositivas, a gravidez ocorreu de formas distintas: a gravidez inesperada e a gravidez desejada.

As mulheres que viveram a experiência de uma gravidez inesperada não queriam outra gravidez, por já serem mães de filhos que submeteram-se à terapia anti-retroviral. Ansiavam pelo resultado definitivo do teste anti-HIV das crianças. Visualizavam a possibilidade de o filho tornar-se soropositivo, e não desejavam que a criança sofresse discriminações e preconceitos, além do sofrimento agregado à condição de soropositividade.

Descobrir-se grávida sem planejamento levou-as a reações de pânico e de desespero por não conseguir enfrentar o fato, prejudicando, a princípio, sua identificação com a condição de ser/estar grávidas. Estas gestantes demonstram receio de ter um filho soropositivo.

"[...] eu entrei em pânico, desespero [...]"

"[...] jamais eu queria colocar uma pessoa no mundo que poderia ser soropositiva também $[\ldots]$ "..

As mulheres passam por uma fase em que pensam na alternativa do aborto para interromper a gravidez inesperada visando poupar-se da sujeição ao tratamento, ao preconceito e à discriminação social.

$$
\text { "[... }] \text { a minha primeira vontade foi de tirar [...]" }
$$

Por outro lado, atribuem a si a responsabilidade por ter se permitido engravidar sabendo que não desejavam mais ter filhos. Nesse sentido, consideram um erro ter engravidado, porém acreditam ser moral e espiritualmente incorreto e injusto abortar para resolver o problema, além do que esta conduta poderia acarretar complicações para si.

"[...] foi um erro en estar grávida agora, sabendo que eu tenho este problema $[. .$.$] "$

Verificou-se que, ao tomar ciência da gravidez, algumas mulheres reagiram de forma resignada com aceitação como um 
fato natural, sem rejeição e nem cogitação da possibilidade de abortar. Outras, por descobrirem tardiamente a gravidez, não tiveram escolha, a não ser aceitar e assumir.

"[...] com o passar do tempo eu acabei me acostumando [...]"
"[...] eu não queria, mas já estava com quatro meses quando descobri $[. .]$.

Houve gestantes que deliberada e conscientemente, planejaram ter um filho. A vontade de se sentirem mães, mesmo dentre aquelas que já tiveram outros filhos, e que, por contingências diversas, não puderam exercer plenamente o papel de mães e, por querer satisfazer o desejo do parceiro com quem vivem mostram-se como motivações que as levam a engravidar.

"[...] eu ter vontade de ser mãe realmente [...]"

"[...] en já tive duas crianças... uma faleceu.... e o outro eu perdi pra justiça.... uma faleceu porque en não sabia que tinha o problema, en amamentei e ela faleceu do HIV [...]"

Confiança na probabilidade de o bebê soronegativar é a crença das mulheres que se submetem ao acompanhamento e ao tratamento frente às informações sobre a probabilidade de gestar e de ter um filho soronegativo, desde que ambos se submetam à terapia anti-retroviral. Esta informação é condicionante para que elas decidam engravidar e acreditem que têm grande chance de o filho soronegativar.

"[...] foi principalmente eu saber que eu poderia ser soropositivo e o meu filho não. Isso daí me deu coragem de engravidar ... quando eu resolvi engravidar sabendo que en era HIV positivo, eu resolvi porque eu sabia que existia uma probabilidade enorme de eu ser soropositivo e meu filho não [...]"

3. Assumir a gravidez:. Esta categoria retrata a experiência das mulheres soropositivas após superarem a fase de se descobrirem grávidas.

As gestantes soropositivas atribuem significado à atual gravidez e à maternidade. O filho que esperam passa a ser razão e sentido de sua vida neste momento. Para aquelas que não desejavam a gravidez, a chegada de um novo bebê significa a oportunidade de viver uma experiência que necessitam levar adiante e darem um sentido positivo para esta vivência. Para as mulheres cuja gravidez era desejada, a gestação é a concretização do projeto de vida estabelecido de tornarem-se mães e poder construir a identidade materna. O cuidar de si para impedir a evolução da doença deixa de ser a única razão e sentido de sua vida. A prioridade para se cuidar, acima de tudo, visa evitar que o filho se torne soropositivo.

"[...] A minha vida né... tá girando em torno do meu filho e não da minha doença $[. .$.$] "$

"[...] a única coisa que en quero é salvar ele... é ver meu filho, é criar meu filho $[\ldots]$ "

Preparar-se para viver o papel materno caracteriza-se pelas ações das gestantes quanto ao planejamento de funções relacionadas à maternidade que deverão assumir, assim que o filho nascer. Ter de abrir mão da amamentação é um fato que começa a ser elaborado durante a gestação, isto frustra as expectativas das gestantes soropositivas quanto ao papel materno idealizado para si. As gestantes antevêem os cuidados que realizarão para o tratamento do filho. Antecipar o tratamento da criança e a exposição a que estará submetida são pontos que as levam a se preocupar e sofrer antecipadamente, entretanto preparam-nas para encontrar forças e determinação interna para enfrentar o período após o nascimento do filho. As gestantes que já tiveram experiências prévias de ter um filho sendo soropositivas têm expectativas de que com o bebê que estão gerando será realizado o mesmo tratamento imposto ao outro filho.

“[...] por situações que nós já conhecemos, temos de fazer esse sacrificio (não amamentar), pra mim será um sacrifício, porque é muito difícil, acho que será a coisa mais difícil [...]”"

\section{DISCUSSÃO}

A discriminação percebida pela mulher no ambiente social, observada neste estudo, confirma aspectos culturais encontrados na literatura sobre o tema, onde esta situação é relacionada diretamente à condição de soropositividade. Os estudos apontam que viver com a infecção gera medo da rejeição social e da discriminação. Este estudo mostrou que as gestantes soropositivas esforçavam-se para ser a melhor mãe, porém sua condição de soropositividade as impelia ao isolamento sócial ${ }^{(7-8)}$.

Estudo realizado com trabalhadoras de enfermagem de maternidades da região da Grande Florianópolis, SC, confirma esta constatação, pois a rejeição social e a discriminação, percebidas pela mulher HIV positivo, confirmam-se pela afirmação das pesquisadas que, ao cuidar da puérpera soropositiva, vêem-na como alguém que está fora de contexto, impregnada de preconceito e de estigma social. Outro fato de relevância é a não valorização dos reais sentimentos desta mulher que engravida ${ }^{(9)}$.

Ainda que diante da preocupante situação de se verem gestantes com sorologia positiva para o HIV, as mulheres não perderam o sentido de viver, como mostraram os resultados deste estudo. A espera do bebê fortaleceu sua vontade de continuarem vivas. Resultados semelhantes foram encontrados em pesquisa realizada com gestantes soropositivas para o HIV, no município de São Carlos, SP, que mostrou que essas mulheres adquirem forças para aceitar a condição de portadoras do vírus da Aids, no desejo de ver os filhos crescer e no apoio recebido dos familiares. Quando vêem sua morte antecipada pela Aids, têm o desejo de viver o maior tempo possível, a fim de garantir a independência dos filhos ${ }^{(10)}$.

Outra condição que permeia a vida da gestante infectada, identificada neste estudo, reside na recomendação de não oferta do leite materno. Este garante um risco letal para o recém-nascido, e norteia a intenção materna de não amamentá-lo em nenhum momento após o nascimento. $\mathrm{O}$ reconhecimento desta condição, na contra-mão dos programas de incentivo ao aleitamento materno, foi também verificado em pesquisa realizada com mulheres soropositivas, residentes no Distrito Federal: não poder amamentar é a etapa de mais difícil da aceitação, pois ao não amamentar percebem a pressão social, porque agem contrariamente ao papel social de mãe esperado pela sociedade ${ }^{(11)}$.

A identificação social da condição de soropositividade leva a 
gestante a preocupar-se com a exposição do filho em serviços de saúde que, a seu ver, gera preconceito e estigmatização. Fato semelhante foi verificado em estudo realizado com pais de bebês expostos ao HIV, na cidade de Sorocaba, SP, no qual, constatouse a percepção materna sobre preconceito voltado aos bebês identificados como possivelmente infectados. Esta situação faz com que as mães se preocupem em proteger o recém-nascido de comentários e olhares em seu cotidiano ${ }^{(8)}$.

Outro fato a se ressaltar é a fé em Deus, também expressa pelas gestantes do presente estudo. A fé é tida como algo que possibilita a continuidade da vida saudável, mesmo diante da infecção pelo HIV. Em ambos os estudos, assim como em outros encontrados na literatura, a crença na entidade religiosa possibilita o enfrentamento destas pessoas na convivência com o bebê exposto e com seu meio familiar e social ${ }^{(8)}$.

\section{CONCLUSÃO}

Esta pesquisa permitiu concluir que os filhos são a inspiração para as gestantes soropositivas para o HIV manterem-se fortes e não se entregarem à Aids. A gestação é um dos motivos para não

\section{REFERÊNCIAS}

1. Paiva MS. Vivenciando a gravidez e experienciando a soropositividade para o HIV [tese]. São Paulo: Escola de Enfermagem da Universidade de São Paulo; 2000.

2. Moreno CCGS, Rea MF, Filipe EV. Mães HIV positivo e a nãoamamentação. Rev Bras Saúde Matern Infant. 2006;6(2):199-208.

3. Demarco R, Lynch MM, Board R. Mothers who silence themselves: a concept with clinical implications for women living with HIV/AIDS and their children. J Pediatr Nurs. 2002;17(2): 89-95.

4. Creswell JW. Qualitative procedures. In: Creswell JW. Research design: qualitative, quantitative, and mixed methods approach. 3rd ed. Thousand Oaks, Calif.: Sage Publications; c2009. p. 173-202.

5. Blumer H. Symbolic interactionism: perspective and method. Englewood Cliffs, N.J.: Prentice Hall; [1969].

6. Taylor SJ, Bogdan R. Introduction to qualitative research methods: the search for meanings. 2nd ed. New York: Wiley; c1984. perderem o sentido de viver, enquanto a espera do bebê fortalecelhes a vontade de continuarem vivas. Porque reduzem a possibilidade de transmissão vertical do HIV, os medicamentos anti-retrovirais são incentivos para estas mulheres prosseguirem com a gravidez.

Ficou evidente que estas gestantes têm, como objetivo, fazer tudo o que for preciso para que o bebê seja soronegativo, e para que elas próprias se mantenham saudáveis para poder cuidar da criança que estão gerando e dos demais filhos. Elas acreditam nos efeitos dos medicamentos anti-retrovirais para a cura do bebê.

Outra conclusão possível foi a tristeza dessas gestantes por saberem que não podem amamentar seus bebês, embora estejam decididas a renunciar ao ato que consideram de amor, para terem um filho saudável. São mulheres preocupadas com a saúde do filho e que acreditam que, pela fé, Deus poderá fazer com que seu bebê seja soronegativo para o HIV.

Conhecer como as gestantes soropositivas para o HIV percebem a geração de um filho com riscos de infecção, e sabendo das ações que realizam para ter como resultado da gravidez uma criança saudável, vale como norte para os profissionais da área da saúde envolvidos em seu atendimento, no sentido de promover ações educativas pertinentes às demandas dessas mulheres.
7. Praça NS. Aspectos culturais e a infecção pelo HIV na mulher. In: Paula CC, Padoin SMM, Schaurich D, organizadores. Aids: o que ainda há para ser dito? Santa Maria: Editora UFSM; 2007. p.127-42.

8. Almeida JM. Projeto transmissão vertical zero: expectativas e ações de pais soropositivos para o HIV à espera do diagnóstico do filho. [Tese]. São Paulo: Escola de Enfermagem da Universidade de São Paulo; 2008.

9. Monticelli M, Santos EKA, Erdmann AL. Ser-mãe HIV-positivo: significados para mulheres HIV positivo e para a Enfermagem. Acta Paul Enferm. 2007;20(3):291-8.

10. Ruggiero EMS. Gestante portadora do vírus HIV: vida e significado [tese]. Ribeirão Preto: Escola de Enfermagem de Ribeirão Preto da Universidade de São Paulo; 2000.

11. Sant'Anna ACC, Seidl EMF, Galinkin AL. Mulheres, soropositividade e escolhas reprodutivas. Estud Psicol (Campinas). 2008;25(1):101-9. 